\title{
TROPHIC RELATIONSHIPS IN ORCHID MYCORRHIZA - DIVERSITY AND IMPLICATIONS FOR CONSERVATION
}

\author{
HANNE. N. RASMUSSEN ${ }^{1,3} \&$ FINN N. RASMUSSEN ${ }^{2}$ \\ ${ }^{1}$ Dept. of Forestry, University of Copenhagen, Hoersholm Kongevej 11, Hoersholm 2970, Denmark \\ ${ }^{2}$ Dept. of Biology, University of Copenhagen, Gothersgade 140, Copenhagen 1123, Denmark \\ ${ }^{3}$ Author for correspondence: hnr@kvl.dk
}

KEY WORDS: food limitation, heterotrophy, life history, mycophagy, predator-prey, senile populations

\section{Introduction}

Orchid species are perennial, and though demographic data suggest that the family includes $r-$ as well as K-strategists (Whigham \& Willems 2003), most species are potentially long-lived. Individual plants may be kept in living plant collections or in nature reserves for practically unlimited periods of time. There are several reports on natural populations suspected of little or no seedling recruitment, "senile populations" (Tamm 1991, Rasmussen 1995), especially among rare orchids under critical surveyance. Such populations may function as a seed source to neighbouring areas but are likely to eventually disappear from the site.

Sustainable conservation thus requires the preservation of conditions that enable the species to carry through its entire life cycle. The conservational concern should also involve species of other organisms that are associated during a critical life stage, such as a pollinator during flowering, or a symbiotic fungus during seed germination (Zettler et al. 2003). Not only that, but the requirements of these organisms must be considered, such as appropriate substrates for the fungi. Clearly, "orchids require an ecosystem approach to their conservation" (Roberts 2003).

In light of recent research, the orchid-fungus relationship has proved particularly complex, as it may be subject to trophic changes during the lifetime of the orchid. The degree of specificity, and the paths of biological energy are major concerns in these relationships. All of this may need to be assessed in cases of severely endangered orchid species.

\section{Orchid mycorrhiza is still considered a unilateral relationship}

Transport of carbohydrates from fungi to seedlings of orchids has been amply demonstrated, beginning with Smith's experiments $(1966,1967)$. There is no other feasible explanation for the long-term deficiency in the photoassimilating apparatus known from orchid seedlings generally and adult stages widespread in the family (e.g, Girlanda et al. 2006). Recent stable isotope analyses support the fungal origin of a significant part of the $\mathrm{C}$ and $\mathrm{N}$ found in aboveground structures of orchids (Gebauer \& Meyer 2003, Julou et al. 2005). Hyphal coils within the orchid tissues become degraded by an enzymatic process and transfer is assumed to occur entirely or predominantly over a dead fungal interface, as ultrastructural studies suggest (Peterson et al. 1996). This further adds to the evidence of an asymmetric relationship, with the orchid as the receiving and dependent part.

A recent report stating mutualism in orchid-fungus relationships (Cameron et al. 2006) was based on a set of special experimental circumstances: Surface sterilized plantlets were planted on an inert agar, and internal hyphae from within the rhizome were allowed to colonize the agar. When ${ }^{14} \mathrm{CO}_{2}$ was subsequently supplied to the leaves, about $2 \%$ of the photoassimilated labeled carbon could later be traced to the mycelium. Physiologically interesting as this may be, it is important to note that the result was obtained under an extreme starvation of the mycelium. Such conditions would hardly ever occur under field conditions where complex carbon 
sources abound. Furthermore, we do not know whether the transfer occurred via an intact plant interface surrounding hyphal pelotons. Field studies suggest that low substrate carbon supply may increase the virulence of the fungi and turn the situation into parasitism of the fungus on the orchid (Beyrle et al. 1995).

\section{Orchids are never "fully autotrophic"}

Seedlings of Neuwiedia veratrifolia, belonging to the subfamily Apostasioideae, usually considered the most basal in orchid phylogeny, were found for the first time by Kristiansen et al. (2001). They develop typical protocorms with pelotons, and the fungi associated with them in the wild proved to belong to Tulasnella and Thanathephorus, two genera that are known to develop Rhizoctonia-stages (Kristiansen et al., 2004). VAM is the only type of mycorrhiza found in monocotyledons outside of Orchidaceae, and it seems a plausible scenario that ancestors of the orchid family developed a seedling mycotrophy, based on invasive saprotrophic rhizoctonioid mycelia in conjunction with the evolution of micro-seeds. From the beginning the whole range of this rather mixed assembly of imperfect mycelia of Basidiomycetes (i.e., Rhizoctonia s.1., Table 1, below) appears to have been employed.

Orchid seed evolution seems to have run towards further reduction in size, the epiphytic orchid groups tending to produce smaller seeds than terrestrials (Rasmussen, 1995). Assuming an evolutionary reduction of seed nutrient reserves within the orchid family clade, a secondary loss of seedling mycotrophy appears unlikely, and is not supported by any observations so far. In other words: seedling mycotrophy seems to be a uniquely derived and omnipresent orchid character.

Plant seedlings generally begin life by utilizing seed reserves that consist of stored photoassimilates from their autotrophic mother plant. In contrast, the orchid seedling relies not only on reserves from the mother plant but also on carbohydrates from mycotrophy. Otherwise the seedlings will not develop in the field. Thus, if the whole life history is considered, orchids are never fully autotrophic. When this description is sometimes used about orchids (e.g., "the fully autotrophic Listera ovata", Girlanda et al., 2006), this either refers to the adult stage only, or must be considered a slip of the pen.

In terms of preserving an orchid species, this means that fungi employed during germination cannot be disregarded. All orchids are to some degree mycoheterotrophic, although this designation has somewhat misleadingly been restricted to species with obviously chlorophyll-deficient adult stages. The sequential or simultaneous combination of mycotrophy and phototrophy, that is charactistic of orchids, may be described as mixotrophy. The only exception from mixotrophy would be the entirely mycotrophic orchids. Cephalanthera damasonium is an example of a species that segregates into holomycotrophic and mixotrophic individuals: the albinos showed no trace of photoassimilation as adult plants, whereas the adult green individuals were found to be mixotrophic with about fifty-fifty contribution of carbon from either system (Julou et al. 2005). Other studies, also based on the distribution of stable carbon and nitrogen isotopes, indicate that green leaved forms may aquire a significant fraction of their $\mathrm{C}$ and $\mathrm{N}$ through fungi, but that species differ considerably in this respect (Gebauer \& Meyer, 2003). Thus orchids are arranged in a continuum from holomycotrophy to various degrees of mixotrophy.

\section{Useful terminology from the animal kingdom}

Taylor (2004) put it aptly: "let's be clear - we are talking about plants that consume fungi." Much confusion may arise from inadequte or misleading designations. The phytobiont (orchid) has colloquially been referred to as the 'host', notwithstanding the fact that the mycobiont is providing the meal! Even worse are anthropomorphic expressions that seem to imply voluntary and mutualistic associations ('marriage', 'fidelity', 'promiscuity'), or deception ('cheater') which suggests a previous mutualism or presupposes a "normal" behavior deviated from. Even the idea of 'specificity' implies a degree of mutual selection. Such expressions should be avoided as they are inconsistent with our observations and present knowledge. 
TABLE 1. Above: Examples of orchid-fungus-substrate relationships. Below: Fungus genera mentioned above, listed with taxonomic position according to Kirk et al. 2001.

Orchid species Trophic stage

Provider/Prey

Ultimate food source

Neuwiedia veratrifolia: individually monophagous? (Kristiansen et al. 2004)

seedling mycotrophy

Tulasnella Thanathephorus

leaf litter (Kristiansen

et al., 2001)

adult mycotrophy

adult phototrophy

Tulasnella sp., Thanathephorus sp.

leaf litter

Cypripedium, several species: mono-oligophagous (Shefferton et al. 2005)

$$
\begin{aligned}
& \text { seedling mycotrophy } \\
& \text { adult mycotrophy } \\
& \text { adult phototrophy }
\end{aligned}
$$

Tulasnellaceae $\quad$ organic debris

Goodyera pubescens and Liparis lilifolia: mono(-oligo)phagous (McCormick et al. 2004)

$\begin{array}{cll}\text { seedling mycotrophy } & \text { Tulasnella } \text { cf. bifrons } & \text { organic debris } \\ \text { adult mycotrophy } & \text { Tulasnella } \text { cf. bifrons } & \text { organic debris } \\ \text { adult phototrophy } & \end{array}$

Epipactis microphylla: oligophagous (Selosse et al. 2004)

$$
\begin{gathered}
\text { seedling mycotrophy } \\
\text { adult mycotrophy } \\
\text { phototrophy (in green individuals) } \\
\text { and not (in albinos) }
\end{gathered}
$$

Tuber?

mainly Tuber cf. excavatum

live trees $(\mathrm{ECM})$

Neottia nidus-avis: oligophagous, locally monophagous? (McKendrick et al. 2002, Selosse et al. 2002)

\begin{tabular}{|c|c|c|}
\hline seedling mycotrophy & Tomentella $\mathrm{sp}$. & $\begin{array}{c}\text { large woody debris } \\
\text { Rasmussen \& Whigham 1998) }\end{array}$ \\
\hline adult mycotrophy & $\begin{array}{l}4 \text { groups of tulasnelloids } \\
+ \text { some persistance of Tomentella }\end{array}$ & a organic debris \\
\hline
\end{tabular}

$\begin{array}{lll}\text { seedling mycotrophy } & \text { Sebacina } & \text { live trees (ECM) } \\ \text { adult mycotrophy } & \text { Sebacina } & \text { live trees (ECM) } \\ \text { no phototrophy } & & \\ \text { cited in Mckendrick } \text { et al. 2002) } & & \end{array}$

(sources cited in Mckendrick et al. 2002)

Limodorum abortivum: oligophagous, obligate fungal switch? (Girlanda 2006)

$$
\begin{gathered}
\text { seedling mycotrophy } \\
\text { adult mycotrophy } \\
\text { very little phototrophy }
\end{gathered}
$$

$\begin{array}{lc}\text { Ceratobasidium? } & \text { organic debris } \\ \text { Russula } \text { spp. } & \text { live trees (ECM) }\end{array}$

Tipularia discolor: switch from germination fungus, polyphagous as adult (McCormick et al. 2004)

Corallorhiza trifida: monophagous (McKendrick et al. 2000a+b)

\begin{tabular}{ccc}
$\begin{array}{c}\text { seedling mycotrophy } \\
\text { adult mycotrophy } \\
\text { no phototrophy }\end{array}$ & Tomentella & Salix and Betula ECM \\
& & Salix and Betula ECM \\
\hline
\end{tabular}

Epidendrum rigidum: monophagous (Pereira et al. 2005)

$\begin{array}{cll}\text { seedling mycotrophy } & \text { Epulorhiza } & \text { ? saprophyte } \\ \text { adult mycotrophy } & \text { Epulorhiza } & \text { ? saprophyte } \\ \text { adult phototrophy } & & \end{array}$

Hexalectris spicata: oligophagous (Taylor et al. 2003)

$$
\begin{gathered}
\text { seedling mycotrophy } \\
\text { adult mycotrophy } \\
\text { chlorophyll deficient }
\end{gathered}
$$

?

Sebacinaceae+ Thanathephorus live trees $(\mathrm{ECM})$ ? 
TABle 1. Continue.

\begin{tabular}{|c|c|c|c|}
\hline Orchid species & Trophic stage & Provider/Prey & Ultimate food source \\
\hline \multicolumn{4}{|c|}{ Gastrodia elata: serial monophagy, obligate switch of fungus (Xu \& Guo, 2000) } \\
\hline & $\begin{array}{l}\text { seedling mycotrophy } \\
\text { adult mycotrophy } \\
\text { no phototrophy }\end{array}$ & $\begin{array}{l}\text { Mycena osmundicola } \\
\text { Armillaria mellea } \text { s.l. }\end{array}$ & $\begin{array}{c}\text { leaf litter } \\
\text { live and dead wood }\end{array}$ \\
\hline \multicolumn{4}{|c|}{ Epipogium roseum: oligophagy? Yamato et al. 2005} \\
\hline & $\begin{array}{l}\text { seedling mycotrophy } \\
\text { adult mycotrophy } \\
\text { no phototrophy? }\end{array}$ & $\begin{array}{c}? \\
\text { Coprinus }+ \text { Psathyrella }\end{array}$ & dung, dead wood \\
\hline Teleomorph & Anamorph & \multicolumn{2}{|r|}{ Order and class } \\
\hline \multicolumn{2}{|l|}{ Armillaria mellea } & \multicolumn{2}{|r|}{ Agaricales Basidiomycetes } \\
\hline Ceratobasidium & Ceratorhiza (Rhizoctonia s.1.) & Ceratobasidiaceae & Ceratobasidiales Basidiomycetes \\
\hline Coprinus & & Coprinaceae & Agaricales Basidiomycetes \\
\hline Mycena & & Tricholomataceae & Agaricales Basidiomycetes \\
\hline Psathyrella & & Coprinaceae & Agaricales Basidiomycetes \\
\hline Russula & & Russulaceae & Russulales Basidiomycetes \\
\hline Sebacina & Epulorhiza (Rhizoctonia s.1.) & Exidiaceae & Tremellales Basidiomycetes \\
\hline Thanathephorus & Rhizoctonia s.str. & Ceratobasidiaceae & Ceratobasidiales Basidiomycetes \\
\hline Tomentella & & Thelephoraceae & Thelephorales Basidiomycetes \\
\hline Tuber & & Tuberaceae & Pezizales Ascomycetes \\
\hline Tulasnella & Epulorhiza (Rhizoctonia s.1.) & Tulasnellaceae & Tulasnellales Basidiomycetes \\
\hline
\end{tabular}

It seems about time to acknowledge that orchids are mycophagous and that the orchid-fungus association is more like a predator-prey-relationship. A set of concepts and terminology from the zoological vocabulary comes to mind. Recent research has revealed a trophic diversity in orchids so great that we need these concepts to encompass the whole range. Thus, we have examples of orchids with a broad food selection (i.e. polyphagous), the diet spanning several fungal families (Tipularia discolor, Table 1) as well as examples of orchids that are oligophagous, utilizing a minor group of related fungi. Verification of strict monophagy requires the analysis of the plant species through much of its geographic and ecological range. Normally monophagy would be an orchid species-to-fungal species relationship but it might also exist on the individual level, as shown in Goodyera pubescens (McCormick et al. 2006). In this species germina- tion could be carried out with a range of Rhizoctonia spp., but the first strain to infect an individual protocorm seemed to be subsequently preferred. Young plants of Goodyera pubescens only rarely switched from their initial fungus, which shows a surprising ability of seedlings to discriminate hyphae. When a switch was induced experimentally, it carried a considerable risk of mortality.

Nevertheless, an obligate switch of fungus at some point during adolescence is well documented in Gastrodia elata, that is known to germinate on Mycena osmundicola and switch to Armillaria mellea later (i.e. serial monophagy). There are no reports of other food sources for $G$. elata and the switch appears to be necessary for life cycle progression $(\mathrm{Xu} \& \mathrm{Guo}$ 2000). The same applies to Tipularia discolor (McCormick et al. 2004), along with a successional change in the growing environment (Rasmussen \& Whigham 1998). 
Fungal switch may be a more wide-spread phenomenon, however. The sporadic occurrence of various Rhizoctonia mycelia in adult orchids otherwise feeding on ectomycorrhizal fungi as noted by Taylor et al. (2003), Selosse et al. (2004) and Girlanda et al. (2006) might be traces of persisting germination fungi. This parallels the situation in which Rhizoctonia pelotons are sporadically found in orchid species that go almost entirely phototrophic soon after germination (Bayman et al. 2002).

\section{Conservational implications}

The identification of the fungi carries a great deal of information about the natural requirements of the orchid species, since the ultimate food sources may be identified, be it leaf litter, woody debris or certain live host trees (Table 1). In a conservation context that would enable the detection of recruitment sites or encouragement of new ones (Batty et al. 2001).

A broad food selection may render an orchid species comparatively robust to environmental changes. On the other hand, the generalist strategy is considered costly in terms of defence mechanisms to keep the fungi from becoming virulent. The mono- or oligophagous orchid can be optimally adapted to a narrow food selection but is more likely to experience food limitation that might prevent sexual reproduction and threaten individual survival, if photosynthesis is not a sufficient option. It would also be more dependent on the quality of this narrow food base.

Assessing the relative importance of phototrophic assimilation is also important, because this identifies the light requirements of the orchid species in question. The epilithic Lepanthes rupestris appears to be an example of fungal dependency ending soon after germination (Bayman et al. 2002), pelotons being extremely rare in the roots of young and more mature plants at two sites studied (but no leafless seedlings were seen). The same seems to apply to several species of Cypripedium and many epiphytic species, the canopy environment probably offering opportunities for a largely phototrophic existence. The holomycotrophic species, of course, represent the other extreme, being able to survive in deep shade or even as entirely subterraneans (Rhizanthella).

Over and above specific inherited trophic traits there is, of course, in many orchids a phenotypic plasticity in respect to mycotrophic persistence, which is influenced by the growing conditions offered at each site and time. For instance, a lack of mycorrhizal infection in adult plants needs not be interpreted as an inherently low dependence on mycotrophy. The plants in question could simply be optimizing their individual survival in an environment with much light and exhausted fungal food sources.

\section{Evolutionary considerations}

Rhizoctonia-based seedling mycotrophy was probably the first step in the evolution of orchid mycorrhiza, possibly from an arbuscular mycorrhiza-dependent ancestor, and hence is a plesiomorphic condition within Orchidaceae. The adult orchid would be expected to be at first predominantly phototrophic, as in non-mycorrhizal or arbusculardependent ancestors. However, an obvious adaptation to a rich fungal food supply and/or limiting light would be a paedomorphic extension of the

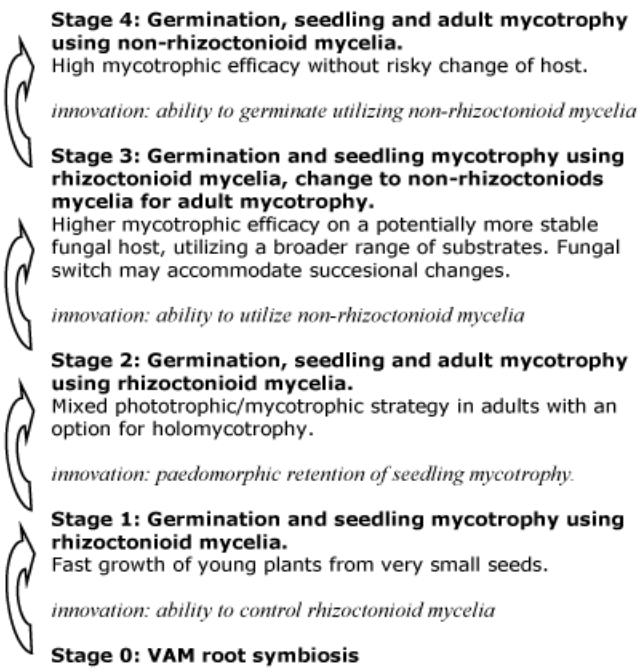

FIGURE 1. Hypothetical steps in the evolution of orchid mycorrhiza from stage 0 , the non-orchid ancestor. See text for actual examples of species demonstrating the stages. Obligate ontogenetic switch of fungal host is known to occur in stage 3 orchids. It is likely that stages 1-4 have evolved several times, but it is unknown to what extent reversal may happen. 
Rhizoctonia-dependency into adult life history (Fig. 1 , stage 1 to 2 ).

Retention of this seedling mycotrophy combined with alternative fungal food sources in adult plants could be the next step in optimization of mycophagy. This evolution in orchids might be accelerated by ample available biomass of fungal species that for some reason are unable to trigger orchid seed germination. The challenges would consist of inducing initial invasion and peloton formation from mycobionts whose biology does not predispose them for entering living plant tissue, and futhermore developing novel defence mechanisms taylored to keep that infection under control (Fig. 1, stage 3).

The ultimate adaptation to such alternative food sources would be evolution of compatibility of the fungus to orchid seeds and the germination process (Fig. 1, stage 4). So far, germination by nonRhizoctonia (in the broadest sense) has only been documented within a few, advanced orchid groups: Tipularia and Corallorhiza, Gastrodia (Table 1) and possibly Cyrtosia (Galeola) septentrionalis (discussed in Rasmussen, 1995).

We do not know if there is any impact on fungal fitness and evolution by this symbiosis. One might speculate that orchid predation is too slight to impact on fungal life strategies. As for the fitness, low fruiting body production has been reported in mycelia that support orchids as compared to mycelia of related fungal species (Jones \& Smith, 2004, Taylor \& Bruns, 1999).

\section{Conclusions}

- Orchid mycorrhiza is a non-mutualistic symbiosis and it is practical to think of it as a predator-prey or parasite-provider relationship, with the orchid as the beneficiary. Terms implying mutualism or defection from a presupposed mutualism are misleading.

- The entire life history is important in conservation of orchid species. Fungi that assist in germination are essential.

- Fungi involved in the various life phases need to be identified and their contribution to growth of the orchid assessed, be it brief or lasting, high or low.
- The ultimate food source in mycotrophy, i.e., the substrate for fungal preys needs to be rated as a maintaining factor for the orchid population in question.

\section{LiTERATURE CITED}

Batty, A.L., K.W Dixon, M. Brundrett \& K. Sivasithamparam. 2001. Constraints to symbiotic germination of terrestrial orchid seed in a mediterranean bushland. New Phytol. 152 : 511-520.

Bayman, P., E.J. González, J.J. Fumero \& R.L. Tremblay. 2002. Are fungi necessary? How fungicides affect growth and survival of the orchid Lepanthes rupestris in the field. J. Ecol. 90 : 1002-1008.

Beyrle, H.F., S.E. Smith, R.L. Peterson \& C.M.M. Franco. 1995. Colonization of Orchis morio protocorms by a mycorrhizal fungus: Effects of nitrogen nutrition and glyphosate in modifying the responses. Can. J. Bot. 73 : 1128-1140.

Cameron, D.D., J.R. Leake \& D.J. Read. 2006. Mutualistic mycorrhiza in orchids: evidence from plant-fungus carbon and nitrogen transfers in the green-leaves terrestrial orchid Goodyera repens. New Phytol. 171 : 405-416.

Gebauer, G. \& M. Meyer. 2003. ${ }^{15} \mathrm{~N}$ and ${ }^{13} \mathrm{C}$ natural abundance of autotrophic and mycotrophic orchids provides insight into nitrogen and carbon gain from fungal association. New Phytol. 160 : 209-223.

Girlanda, M., M.A. Selosse, D. Cafasso, F. Brilli, S. Definer, R. Fabbian, S. Chignone, P. Pinellli, R. Segreto, F. Loreto, S. Cozzolino \& S. Perotto. 2006. Inefficient photosynthesis in the Mediterranean orchid Limodorum abortivum is mirrored by specific association to ectomycorrhizal Russulaceae. Molec. Ecol. 15 : 491-504.

Jones, M.D. \& S.E. Smith. 2004. Exploring functional definitions of mycorrhizas: Are mycorrhizas always mutualisms? Can. J. Bot. 82 : 1089-1109.

Julou, T., B. Burghardt, G. Gebauer, D. Berveiller, C. Damesin \& M.-A. Selosse. 2005. Mixotrophy in orchids: insight from a comparative study of green individuals and nonphotosynthetic individuals of Cephalanthera damasonium. New Phytol. 166 : 639-653.

Kirk, P.M., P.F. Cannon, J.C. David \& J.A. Stalpers. 2001. Dictionary of the fungi. 9th. ed. CAB International, Wallingford, UK. 
Kristiansen, K.A., J.V. Freudenstein, F.N. Rasmussen \& H.N. Rasmussen. 2004. Molecular identification of mycorrhizal fungi in Neuwiedia veratrifolia (Orchidaceae). Molecular Phylogenetics and Evolution 33 : 251-258.

Kristiansen, K.A., F.N. Rasmussen \& H.N. Rasmussen. 2001. Seedlings of Neuwiedia (Orchidaceae subfamily Apostasioideae) have typical orchidaceous mycotrophic protocorms. Amer. J. Bot. 88 : 956-959

McCormick, M.K., D.F. Whigham \& J. O’Neill. 2004. Mycorrhizal diversity in photosynthetic terrestrial orchids. New Phytol. 163 : 425-438.

McCormick, M.K., D.F. Whigham, D. Sloan, K. O’Malley \& B. Hodkinson. 2006. Orchid-fungus fidelity: a marriage meant to last? Ecology 87 : 903-911.

McKendrick, S.L., J.R. Leake, D.L. Taylor \& D.J. Read. 2000a. Symbiotic germination and development of myco-heterotrophic plants in nature: ontogeny of Corallorhiza trifida and characterization of its mycorrhizal fungi. New Phytol. 145 : 523-537.

McKendrick, S.L., J.R. Leake \& D.J. Read. 2000b. Symbiotic germination and development of myco-heterotrophic plants in nature: transfer of carbon from ectomycorrhizal Salix repens and Betula pendula to the orchid Corallorhiza trifida through shared hyphal connections. New Phytol. 145 : 539-548.

McKendrick, S.L., J.R. Leake, D.L. Taylor \& D.J. Read. 2002. Symbiotic germination and development of mycoheterotrophic orchid Neottia nidus-avis in nature and its requirement for locally distributed Sebacina spp. New Phytol. 154 : 233-247.

Pereira, O.L., M.C.M. Kasuya, A.C. Borges \& E.F. de Araújo. 2005. Morphological and molecular characterization of mycorrhizal fungi isolated from neotropical orchids in Brazil. Can. J. Bot. 83 : 54-65.

Peterson, R.L., P. Bonfante, A. Faccio \& Y. Uetake. 1996. The interface between fungal hyphae and orchid protocorm cells. Can. J. Bot. 74 : 1861-1870.

Rasmussen, H.N. 1995. Terrestrial orchids. From seed to mycotrophic plant. Cambridge University Press.

Rasmussen, H.N. \& D.F. Whigham. 1998. Importance of woody debris in seed germination of Tipularia discolor (Orchidaceae). Amer. J. Bot. 85 : 829-834

Roberts, D.L. 2003. Pollination biology: the role of sexual reproduction in orchid conservation. Pp. 113-136. In Dixon, K.W., S.P. Kell, R.L. Barrett \& P.J. Cribb (eds).
Orchid conservation. Natural History Publications, Kota Kinabalu, Borneo.

Selosse, M.-A., M. Weiss, J.-L. Jany \& A. Tillier. 2002. Communities and populations of sebacinoid basidiomycetes associated with the achlorophyllous orchid Neottia nidus-avis (L.) LCM Rich. and neighbouring tree ectomycorrhizae. Molec. Ecol. 11 : 1831-1844.

Selosse, M.-A., A. Faccio, G. Scappaticci \& P. Bonfante. 2004. Chlorophyllous and achlorophyllous specimens of Epipactis microphylla (Neottieae, Orchidaceae) are associated with extomycorrhizal septomycetes, including truffles. Microb. Ecol. 47 : 416-426.

Shefferton, R.P., M. Weiss, T. Kull \& D.L. Taylor. 2005. High specificity generally characterizes mycorrhizal association in rare lady's slipper orchids, genus Cypripedium. Molec. Ecol. 14 : 613-626.

Smith, S.E. 1966. Physiology and ecology of orchid mycorrhizal fungi with reference to seedling nutrition. New Phytol. 65 : 488-499.

Smith, S.E. 1967. Carbohydrate translocation in orchid mycorrhizas. New Phytol. 66 : 371-378.

Tamm, C.O. 1991. Behavior of some orchid populations in a changing environment: observations on permanent plots, 1943-1990. Pp 1-13. In Wells, TCE, Willems, JH (eds), Population ecology of terrestrial orchids. The Hague: SPB Academic Publishing.

Taylor, D.L. 2004. Myco-heterotroph-fungus marriages is fidelity over-rated? New Phytol. 163 : 217-221.

Taylor, D.L. \& T.D. Bruns. 1999. Population, habitat and genetic correlates of mycorrhizal specialization in the cheating orchids Corallorhiza maculata and C. mertensiana. Molec. Ecol. 8 : 1719-1732.

Taylor, D.L., T.D. Bruns, T.M. Szaro \& S.A. Hodges. 2003. Divergence in mycorrhizal specialization within Hexalectris spicata (Orchidaceae), a nonphotosynthetic desert orchid. Amer. J. Bot. 90 : 1168-1179

Whigham, D.F. \& J.H. Willems. 2003. Demographic studies and life-history strategies of temperate terrestrial orchids as a basis for conservation. Pp. 137-158 in: Dixon, K.W., S.P. Kell, R.L. Barrett \& P.J. Cribb (eds). Orchid conservation. Natural History Publications, Kota Kinabalu, Borneo.

Xu, J.T. \& S.X. Guo. 2000. Retrospect on the research of the cultivation of Gastrodia elata B1., a rare traditonal Chinese medicine. Chinese Medical Journal 113 : 686-692. 
Yamato, M., T. Yagame, A. Suzuki \& K. Iwase. 2005. Isolation and identification of mycorrhizal fungi associating with an achlorophyllous plant, Epipogium roseum (Orchidaceae). Mycoscience 46 : 73-77.
Zettler, L.W., J. Sharma \& F.N. Rasmussen. 2003. Mycorrhizal diversity. Pp 205-226. In Dixon, KW, Kell, SP, Barrett, RL, Cribb, PJ (eds). Orchid conservation. Natural History Publications, Kota Kinabalu, Borneo.

Hanne N. Rasmussen is senior scientist at the Department of Forestry, Royal Danish Agricultural University (soon to be included in the University of Copenhagen), Denmark. Her research interests in orchids span morphology, cytology, evolution, and physiology of mycorrhizal relationships. She has worked practically with propagation in vitro and with field studies of germination and mycorrhization. The work has been centered on northern hemispheric, terrestrial orchids, but also includes some tropical studies. The publication list comprises 34 papers on various aspects of orchid mycorrhiza, including a scholarly book (Cambridge University Press, 1995), as well as 14 papers on other orchid-related subjects.

Finn N. Rasmussen is associate professor at the Biological Institute, University of Copenhagen, Denmark and member of the "Monocot Research Group" in Copenhagen. His field of research is systematics and evolution of Orchidaceae and other monocotyledones, orchids of tropical Africa and Asia, micromorphology and developmental anatomy, cladistics, pollination biology and mycorrhizal biology of Orchidaceae, evolution of fruits in monocotyledones. His publications comprise a range of papers on these subjects besides university level textbooks in botany and a new complete field guide to the flora of Denmark. Co-editor of "Genera Orchidacearum", member of the IUCN/SSC Orchid Special Group. 